\title{
Low frequency geomagnetic field fluctuations at cap and low latitude during October 29-31, 2003
}

\author{
S. Lepidi, L. Cafarella, L. Santarelli \\ Istituto Nazionale di Geofisica e Vulcanologia, Rome, Italy
}

\begin{abstract}
On October-November 2003 complex interplanetary structures, originated by a series of solar eruptions, hit the Earth, triggering violent Sun-Earth connection events. In this paper we analyze the low frequency geomagnetic field fluctuations detected on the ground during Oct. 29-31, 2003, a time period characterized by extremely high solar wind speed values and by out-of-ecliptic interplanetary magnetic field orientation for intervals of several hours. We analyze geomagnetic field measurements at four high latitude stations located in the polar cap, three in the southern and one in the northern hemisphere. From a comparison with simultaneous measurements at low latitude, we address the question of the global character of the observed phenomena. The results show, for selected time intervals, the occurrence of simultaneous fluctuations at all the stations, with high coherence even between high and low latitude; it is interesting that these fluctuations are detected during open magnetospheric conditions, when the high latitude stations are situated well within the polar cap, i.e. far from closed field lines.
\end{abstract}

Key words: Magnetospheric ULF waves, Sun-Earth connections, polar cap. 


\section{INTRODUCTION}

Several studies analyzed the interaction between coronal ejecta, characterized by long periods of out-of-ecliptic interplanetary magnetic field (IMF) orientation, and the Earth's magnetosphere. While southward IMF conditions are associated with major geomagnetic storms (Farrugia et al., 1996; Lepping et al., 1991; Gopalswamy et al., 2005), during northward IMF conditions solar wind (SW) density enhancements can compress the magnetosphere and trigger geomagnetic field fluctuations (Francia et al., 1999).

In previous papers (Villante et al., 1998; Lepidi et al., 1999) we analyzed the geomagnetic field fluctuations at low and cap latitude triggered by magnetic clouds. In addition to storm signatures, we found at both sites fluctuations following SW pressure variations; we also found, during closed magnetospheric conditions, fluctuations at discrete frequencies (few $\mathrm{mHz}$ ) with high coherence between the stations. These results have been interpreted in terms of global cavity/waveguide modes of the whole magnetosphere which acts as a resonant cavity when excited by external stimulations, such as SW pressure pulses or Kelvin-Helmholtz instability on the magnetopause (Walker et al., 1992; Harrold and Samson, 1992). Evidence for such global magnetospheric oscillations had already been found at auroral latitudes (Samson et al., 1992; Ziesolleck and McDiarmid, 1995), at low latitude (Ziesolleck and Chamalaun, 1993) and even within the polar cap (Villante et al., 1997).

In the auroral region, i.e. the region separating open and closed field lines, intense ionospheric currents can give rise to local variations of the geomagnetic field (Campbell, 1997); around midnight these features are mostly related to substorm occurrence (Olson, 1986). During daytime, typical polar cusp signals are observed in the Pc5 frequency band but they find no correspondence in higher latitude observations (Lanzerotti et al., 1999).

Recent studies (Yagova et al., 2002, 2004) have shown the occurrence of geomagnetic pulsations with frequency of few $\mathrm{mHz}$ specific to the polar cap; these cap pulsations are decoupled from simultaneous auroral activity in the same magnetic local time (MLT) sector.

In this study we focus on the low frequency geomagnetic field fluctuations $(\sim 1-5 \mathrm{mHz})$ observed at high latitude on October 29-31, 2003 when complex interplanetary structures, with anomalous IMF and SW conditions, hit the Earth.

We analyze the geomagnetic field variations at the three Antarctic stations Mario Zucchelli Station (formerly Terra Nova Bay, international geomagnetic observatory code TNB), Scott Base (SBA) and Dumont D'Urville (DRV), at the same geomagnetic latitude but different MLT, and at the Canadian station Cambridge Bay (CBB), at the same MLT and almost 
opposite corrected geomagnetic latitude as TNB (Table 1). The Antarctic stations are located in the southern polar cap, at the footprint of open geomagnetic field lines and around local geomagnetic noon they approach the polar cusp. The Canadian station is located at a slightly equatorward latitude, so during daytime hours it is typically under the polar cusp and in particular magnetospheric conditions it could be even situated at the footprint of closed field lines (Zhou et al., 2000).

In order to ascertain the possible global character of the pulsation trains simultaneously observed at the Antarctic stations, for selected time periods we extended the analysis also to a latitudinal chain of European low latitude stations: Gibilmanna (GIB), L'Aquila (AQU), Castello Tesino (CTS) and Furstenfeldenbruck (FUR), located at the footprint of closed geomagnetic field lines (Table 1).

The analysis is based on 1-min values of the horizontal H component. Stations TNB, GIB, AQU and CTS are run by INGV; data from SBA, DRV, CBB and FUR have been downloaded from INTERMAGNET web site.

Interplanetary data are from ACE spacecraft; regarding SW measurements, standard SWI mode ion data, collected every $64 \mathrm{sec}$, were recorded only from Oct. 31, 0051UT; for preceding period, only STI mode ion data, collected approximately every $33 \mathrm{~min}$, were available (Skoug et al., 2004).

\section{EXPERIMENTAL OBSERVATIONS AND DISCUSSION}

In Fig. 1 we show interplanetary data on Oct. 29-31, 2003, together with Dst index. It can be seen that in the time interval of interest there are several periods with strongly southward IMF: approximately 06-09 UT and 14-03 UT on Oct. 29-30 and 17-01 UT on Oct. 30-31; these periods correspond to strong geomagnetic storms, with Dst index reaching -180 nT, $360 \mathrm{nT}$ and $-400 \mathrm{nT}$, respectively. There are also periods with strongly northward IMF: approximately 03-10 UT on Oct. 30 and 01-11 UT on Oct. 31. Plasma data show exceptionally high SW speed; indeed, it mostly exceeds $1000 \mathrm{~km} / \mathrm{s}$ and, after the interplanetary shocks on Oct. 29, 0558 UT and on Oct. 31, 1619 UT (Skoug et al., 2004), it reaches values around $1700 \mathrm{~km} / \mathrm{s}$. The SW density shows several variations, especially during Oct. 31 .

The variation of the geomagnetic field $\mathrm{H}$ component at the eight stations in the time interval of interest is shown in Fig. 2. It is evident that the geomagnetic activity is intense, especially during the main phase of the geomagnetic storms. It is also evident that the 
geomagnetic variations are always very similar between the low latitude stations; in some time intervals there is a strict similarity between the geomagnetic variations at TNB and at the closest station SBA and sometimes also between TNB and DRV.

Fig. 3 shows, in the upper panels, the dynamic power spectra at the four high-latitude stations and at AQU, taken as reference for the low latitude stations; the spectra are computed from the differenced data (in order to make more evident higher frequency variations) by means of maximum entropy method, at order 20 of the prediction error filter, over 2-hour intervals with a time shift of $30 \mathrm{~min}$. The figure also shows, in the lower panels, the dynamic coherence between couple of stations, computed over 2-hour intervals (with 8 degrees of freedom) with a time shift of $30 \mathrm{~min}$; in the plots the coherence is shown only where the spectral power at high latitude exceeds $10^{4} \mathrm{nT}^{2} / \mathrm{Hz}$.

From the dynamic spectra is evident a strong similarity at the high latitude stations in the time sequence of the broadband major power enhancements, i.e. for several hours from $\sim 06$ UT on Oct. 29 and from $\sim 17$ UT on Oct. 30, corresponding to the onset of geomagnetic storms; however, in both cases the fluctuations are not coherent, even between the two closest stations TNB and SBA. At low latitude, only the onset of the first storm, occurring during local daytime hours, emerges from the power spectrum.

The power spectra show also fluctuations which are observed only at some of the stations, and then can be considered as local phenomena. For example, we note the power peaks at discrete frequencies at 20-21 UT on Oct. 29, only at Antarctic stations and not at the northern high latitude station $\mathrm{CBB}$ nor at low latitude, and the broader power enhancement around 18 UT on Oct. 31, very evident only at CBB.

More interestingly, there are also fluctuations which are simultaneously observed over a wide spatial separation, with high coherence between stations, and then are not just local phenomena. In this sense, we selected for a more detailed analysis three fluctuation events. Two of them, around 23 UT on Oct. 29 and 20 UT on Oct. 30, are observed during southward IMF conditions, in the main phase of strong geomagnetic storms, in correspondence to Dst $350 \mathrm{nT}$ and Dst -300 nT, respectively. The last one, around 11 UT on Oct. 31, is observed during northward IMF conditions, at the end of the recovery phase of a strong geomagnetic storm, and can be related to the SW pressure pulses observed from ACE around 1030 UT.

Fig. 4 shows the analysis of the pulsation event around 23 UT on Oct. 29: the filtered (2.5-5 $\mathrm{mHz}$ ) data (left panels), the power spectra from differenced data (center panels) and the coherence between selected couple of stations (right panels). This event occurs during southward IMF conditions, in the main phase of a strong geomagnetic storm (Dst -350 nT), 
and during high SW speed conditions (V 1000 km/s). Stations TNB, SBA and CBB are in the early magnetic local afternoon sector, DRV in the prenoon sector and the European stations around magnetic midnight.

In the filtered data emerge at all stations a main wave packet between $~ 2250-2315$ UT (less clear at CBB) and a strong damping at $\sim 0015$ UT. From the spectral and coherence analysis we can see that a major power peak emerges at all stations around 2.9-3 mHz; the corresponding fluctuations are highly coherent all over Antarctica and between TNB and low latitude, while at CBB they are completely decoupled. Observations at CBB are coherent with other observatories only at frequencies higher than $3.5-4 \mathrm{mHz}$, but in this frequency range there is a power peak common only to the high latitude, and not also to the European, stations.

Also the event around 20 UT on Oct. 30 (Fig. 5) is observed during southward IMF conditions, in the main phase of a strong geomagnetic storm (Dst -300 nT), and during extremely high SW speed conditions (V 1500-1300 km/s); it could be related to the small SW pressure pulse observed by ACE at $\sim 1930$ UT. TNB, SBA and CBB are around magnetic local noon, DRV in the morning and the European stations in the evening sector.

The filtered data show at all stations a signal intensification just before $20 \mathrm{UT}$, a phase jump around 2020 UT, a strong damping around 2045 UT and a smaller signal intensification just before $21 \mathrm{UT}$; the peak-to-peak amplitude of these pulsations exceeds $100 \mathrm{nT}$ at the Antarctic stations and reaches 30-40 nT at the low latitude stations The spectral and coherence analysis shows that two major power peaks emerge at all stations, around 3.2 and $4.2 \mathrm{mHz}$. The corresponding fluctuations are highly coherent between high latitude stations and also between high and low latitude.

The event around 11 UT on Oct. 31 (Fig. 6) is observed during northward IMF and high SW speed conditions, at the end of the recovery phase of the preceding strong geomagnetic storm; it could be related to the strong SW pressure pulse observed by ACE at 1030 UT. TNB, SBA and $\mathrm{CBB}$ are in the early magnetic morning, DRV in the premidnight sector and the European stations just after local noon. It is interesting to note that in this case the pulsation amplitude at low latitude is comparable, even higher, than at high latitude.

At the Antarctic and low latitude stations a main wave packet starts at $1100 \mathrm{UT}$; in Antarctica it stops at $1130 \mathrm{UT}$, while at low latitude it continues, with increased frequency, for further 15 min. The common Antarctic and low latitude waves between 11-12 UT (Fig. 6, solid lines in the spectral and coherence analysis plots), at $\sim 2.8 \mathrm{mHz}$, are highly coherent all over Antarctica but less coherent between TNB and low latitude. The time sequence of pulsations at CBB is 
different: a main wave packet appears at 1130-1145 UT; it seems to correspond to the final part of the pulsation train at low latitude: indeed, between 11-12 UT there is at all northern hemisphere stations a broader power enhancement with frequency $\sim 3.5 \mathrm{mHz}$, and the corresponding coherence between $\mathrm{CBB}$ and $\mathrm{AQU}$ is very high. In the following hour, between 12-13 UT, a similarity between the wave packets observed at low latitude and CBB emerges; also the power spectra are very similar, with clear power peaks at $\sim 2.5$ and $3.6 \mathrm{mHz}$, and the corresponding coherence is very high (Fig. 6, dashed lines in the spectral and coherence analysis plots); conversely, in this time period fluctuations in Antarctica are completely decoupled not only from those the northern hemisphere, but also all over Antarctica.

\section{SUMMARY}

In this paper we analyze the low frequency geomagnetic field fluctuations detected during Oct. 29-31, 2003 at four high latitude stations within the polar cap, three in the southern and one in the northern hemisphere. From a comparison with simultaneous measurements at low latitude, we address the question of the global character of the observed phenomena. The time period of interest is characterized by extreme values of the SW speed and by several rotations of the IMF, which is strongly southward or strongly northward during time intervals of several hours.

Fluctuations with different characteristics are observed:

- broadband fluctuations at the onset of strong geomagnetic storms, which are observed at all high latitude stations but are not spatially coherent;

- fluctuations observed only at some of the stations, corresponding to local phenomena;

- fluctuations simultaneously observed at all stations which are spatially coherent, even between high and low latitude.

We focus on the spatially coherent fluctuations, selecting three wave packets: two occurring during southward IMF conditions, in the main phase of strong storms, and one during northward IMF conditions, in the recovery phase of a storm.

For both pulsation events occurring during geomagnetic storms, in correspondence to open magnetospheric conditions, the high latitude stations are in the dayside sector, between 07 MLT and 16 MLT. We found that these events are characterized by simultaneous wave packets at discrete frequencies, the same at all the stations; moreover the pulsations are generally highly coherent not only between Antarctic stations, but also between high and low latitude. This result is interesting in that for previous pulsation events triggered by magnetic 
clouds, we had found that the coherence between TNB and AQU attains high values only during closed magnetospheric conditions and when TNB is located close to the local geomagnetic noon (Villante et al., 1998; Lepidi et al., 1999); we had speculated that in a similar situation TNB, which is usually located in the polar cap, reaches minimum distances from closed field lines (Carbary and Meng, 1986), and this is the most favorable condition for a cap station to observe the same phenomena as a low latitude station. Conversely in this particular case, which is characterized by extreme SW speed values, we found evidence for oscillations extending to a major portion of the Earth's magnetosphere, even deep in the polar cap, during open magnetospheric conditions.

On the other hand, some differences emerge, for these two pulsation events occurring during open magnetospheric conditions, in the observations at $\mathrm{CBB}$, which is located close to the northern dayside cusp; in this sense, it is well known that, expecially during open magnetospheric conditions, intense ionospheric currents are present in the auroral oval, giving rise to local geomagnetic field variations (Campbell, 1997).

In the event occurring during closed geomagnetic conditions, the fluctuations are still highly coherent among the Antarctic stations, but not between high latitude opposite hemispheres. In this case, the observations at European stations are definitely more coherent with $\mathrm{CBB}$ than with Antarctic stations. We note that in this case all the high latitude stations are far from the local geomagnetic noon, then the Antarctic stations are located deep in the polar cap. As to $\mathrm{CBB}$, taking into account that the latitude of the auroral oval moves poleward for closed magnetospheric conditions, it could be located in a different magnetospheric region with respect to the Antarctic stations, being surely closer to the auroral oval and to closed field lines. In this sense, our result indicates the occurrence of phenomena extending, in the northern hemisphere, from auroral to low latitudes and the simultaneous occurrence of different phenomena deep in the southern polar cap.

\section{Acknowledgements.}

The research activity at TNB is supported by Italian PNRA. Authors thank Dr. John Steinberg (LANL, USA) for providing STI mode ion data from ACE. 


\section{REFERENCES}

CAMPBELL, W.H. (1997): Introduction to geomagnetic fields, Cambridge Univ. Press, 135142.

CARBARY, J.F. and C.I. MENG (1986): Correlation of cusp latitude with Bz and AE (12) using nearly one years' data, J. GEOPHYS. RES., 91, 10147-1054.

FARRUGIA, C.J., R.P. LEPPING, L.F. BURLAGA, A. SZABO, D. VASILLIADIS, P. STAUNING and M.P. FREEMAN (1996): The WIND magnetic cloud of October 18-20, 1995: implications for the magnetosphere, EOS, Transactions of the American Geophysical Union, 77, 17, S241.

FRANCIA, P., S. LEPIDI, U. VILLANTE, P. DI GIUSEPPE and A.J. LAZARUS (1999): Geomagnetic response at low latitude to continuous solar wind pressure variations during northward interplanetary magnetic field, J. Geophys. Res., 104, 19923-19930.

GOPALSWAMY, N., L. BARBIERI, G. LU, S.P. PLUNKETT and R.M. SKOUG (2005): Introduction to the special event: Violent Sun-Earth connection events of October-November 2003, Geophys. Res. Lett., 32, L03S01, doi: 10.1029/2005GL022348.

HARROLD B.G. and J.C. SAMSON (1992): Standing ULF modes of the magnetosphere: a theory, Geophys. Res. Lett., 19, 1811-1814.

LANZEROTTI L.J,. A. SHONO, H. FUKUNISHI and C.G. MACLENNAN (1999): Longperiod hydromagnetic waves at very high geomagnetic latitudes, J. Geophys. Res., 104, 28423-28435.

LEPIDI S., P. FRANCIA, U. VILLANTE, A. MELONI, A.J. LAZARUS and R.P. LEPPING (1999): The Earth's passage of the April 11, 1997 coronal ejecta: geomagnetic field fluctuations at high and low latitude during northward interplanetary magnetic field conditions, Ann. Geophysicae, 17, 1245-1250.

LEPPING R.P., L.F. BURLAGA, K.W. OGILVIE, B.T. TSURUTANI and A.J. LAZARUS (1991): The interaction of a very large interplanetary magnetic cloud with the magnetosphere and with cosmic rays, J. Geophys. Res., 96, 9425-9438.

OLSON J.V. (1986): ULF signatures of the polar cusp, J. Geophys. Res., 91, 10055-10062.

SAMSON J. C., B.G. HARROLD, J.M. RUOHONIEMI, R.A. GREENWALD AND A.D.M. WALKER (1992): Field line resonances associated with MHD waveguides in the magnetosphere, Gewophys. Res. Lett., 19, 441-444.

SKOUG, R.M., J.T.GOSLING, J.T. STEINBERG, D.J.MCCOMAS, C.W.SMITH, N,F, NESS, Q.HU and L.F. BURLAGA (2004): Extremely high speed solar wind: 29-30 October 
2003, J. Geophys. Res., 109, A09102, doi: 10.1029/2004JA010494.

VILLANTE U., S. LEPIDI, P. FRANCIA, A. MELONI and P. PALANGIO (1997): Long period geomagnetic field fluctuations at Terra Nova Bay (Antarctica), Geophys. Res. Lett., 24, 1443-1446.

VILLANTE, U., P. FRANCIA, S. LEPIDI, M. DE LAURETIS, E. PIETROPAOLO, L. CAFARELLA, A. MELONI, A.J. LAZARUS, R.P. LEPPING and F. MARIANI (1998): Geomagnetic field variations at low and high latitude during the January 10-11, 1997 magnetic cloud, Geophys. Res. Lett., 25, 2593-2596.

WALKER, A.D.M., J.M.RUOHONIEMI, K.B. BAKER, R.A. GREENWALD and J.C. SAMSON (1992): Spatial and temporal behaviour of ULF pulsations observed by the Goose Bay HF radar, J. Geophys. Res., 97, 12187-12202.

YAGOVA, N.V., L.J. LANZEROTTI, U. VILLANTE, V.A. PILIPENKO, S. LEPIDI, P. FRANCIA. V.O. PAPITASHVILI and A.S. RODGER (2002): ULF Pc5-6 magnetic activity in the polar cap as observed along a geomagnetic meridian in Antarctica, J. Geophys. Res., 107, SMP22, doi: 10.1029/2001JA900143.

YAGOVA, N.V., V.A. PILIPENKO, L.J. LANZEROTTI, M.J. ENGEBRETSON, A.S. RODGER, S. LEPIDI and V.O. PAPITASHVILI (2004): Two-dimensional structure of long-period pulsations at polar latitudes in Antarctica, J. Geophys. Res, 109, A03222, doi: 10.1029/2003JA010166

ZIESOLLECK C.W.S and F.H. CHAMALAUN (1993): A two-dimensional array study of low-latitude Pc 5 geomagnetic pulsations, J. Geophys. Res., 98, 13703-13713.

ZIESOLLECK C.W.S. and D.R. MCDIARMID (1995): Statistical survey of auroral latitude Pc 5 spectral and polarization characteristics, J. Geophys. Res., 100, 19299-19312.

ZHOU X.-W., C.T. RUSSELL, G. LE, S.A. FUSELIER, and J.D. SCUDDER (2000): Solar wind control of the polar cusp at high altitude , J. Geophys. Res., 105, 245-251. 


\begin{tabular}{|c|c|c|c|}
\hline Station & Geographic Coord. & Corr. Geom. Coord. & MLT NN (UT) \\
\hline TNB & $74.7 \mathrm{~S} 164.1 \mathrm{E}$ & $80.0 \mathrm{~S} 307.7 \mathrm{E}$ & $20: 11$ \\
\hline SBA & $77.8 \mathrm{~S} 166.8 \mathrm{E}$ & $80.0 \mathrm{~S} 326.5 \mathrm{E}$ & $19: 01$ \\
\hline DRV & $66.7 \mathrm{~S} 140.0 \mathrm{E}$ & $80.4 \mathrm{~S} 235.7 \mathrm{E}$ & $00: 55$ \\
\hline CBB & $69.2 \mathrm{~N} 255.0 \mathrm{E}$ & $77.2 \mathrm{~N} 309.6 \mathrm{E}$ & $19: 54$ \\
\hline FUR & $48.2 \mathrm{~N} 11.3 \mathrm{E}$ & $43.4 \mathrm{~N} 86.9 \mathrm{E}$ & $10: 28$ \\
\hline CTS & $46.0 \mathrm{~N} 11.7 \mathrm{E}$ & $40.8 \mathrm{~N} 86.7 \mathrm{E}$ & $10: 28$ \\
\hline AQU & $42.4 \mathrm{~N} 13.3 \mathrm{E}$ & $36.3 \mathrm{~N} 87.4 \mathrm{E}$ & $10: 24$ \\
\hline GIB & $37.9 \mathrm{~N} 14.0 \mathrm{E}$ & $30.6 \mathrm{~N} 87.3 \mathrm{E}$ & $10: 24$ \\
\hline
\end{tabular}

Table 1. Geographic coordinates, IGRF2003 corrected geomagnetic coordinates and time in UT of the magnetic local noon for the stations. 


\section{FIGURE CAPTIONS}

Figure 1. ACE data (from top: IMF strength and north-south component, SW density and speed) and Dst index.

Figure 2. Variations of the geomagnetic field $\mathrm{H}$ component at the eight stations.

Figure 3. Upper panels: dynamic power spectra from differenced data in logarithmic scale at the four high-latitude stations and at AQU, taken as reference for the low latitude stations (note the different color scale at AQU). Lower panels: dynamic coherence between TNB and each of the other four stations and between CBB and AQU; the coherence is shown only when the spectral power at high latitude exceeds $10^{4} \mathrm{nT}^{2} / \mathrm{Hz}$.

Figure 4. Analysis of the pulsation event around 23 UT on Oct. 29. Upper panels show the observations at high latitude, lower panels at low latitude. From left: filtered $(2.5-5 \mathrm{mHz})$ data, power spectra from differenced data (2230-0030 UT) and coherence (2230-0030 UT). The coherence in the upper panel is between TNB and the other high latitude stations; in the lower panel between TNB-AQU and CBB-AQU.

Figure 5. The same as Fig. 4, for the pulsation train observed around 20 UT on Oct. 30. Power spectra and coherence are computed between 1930-2130 UT.

Figure 6. The same as Fig. 4, for the pulsation train observed around 11 UT on Oct. 31. Power spectra and coherence are computed between 11-12 UT (solid lines) and between 12-13 UT (dashed lines); 12-13 UT power spectra have been down shifted by two decades. 

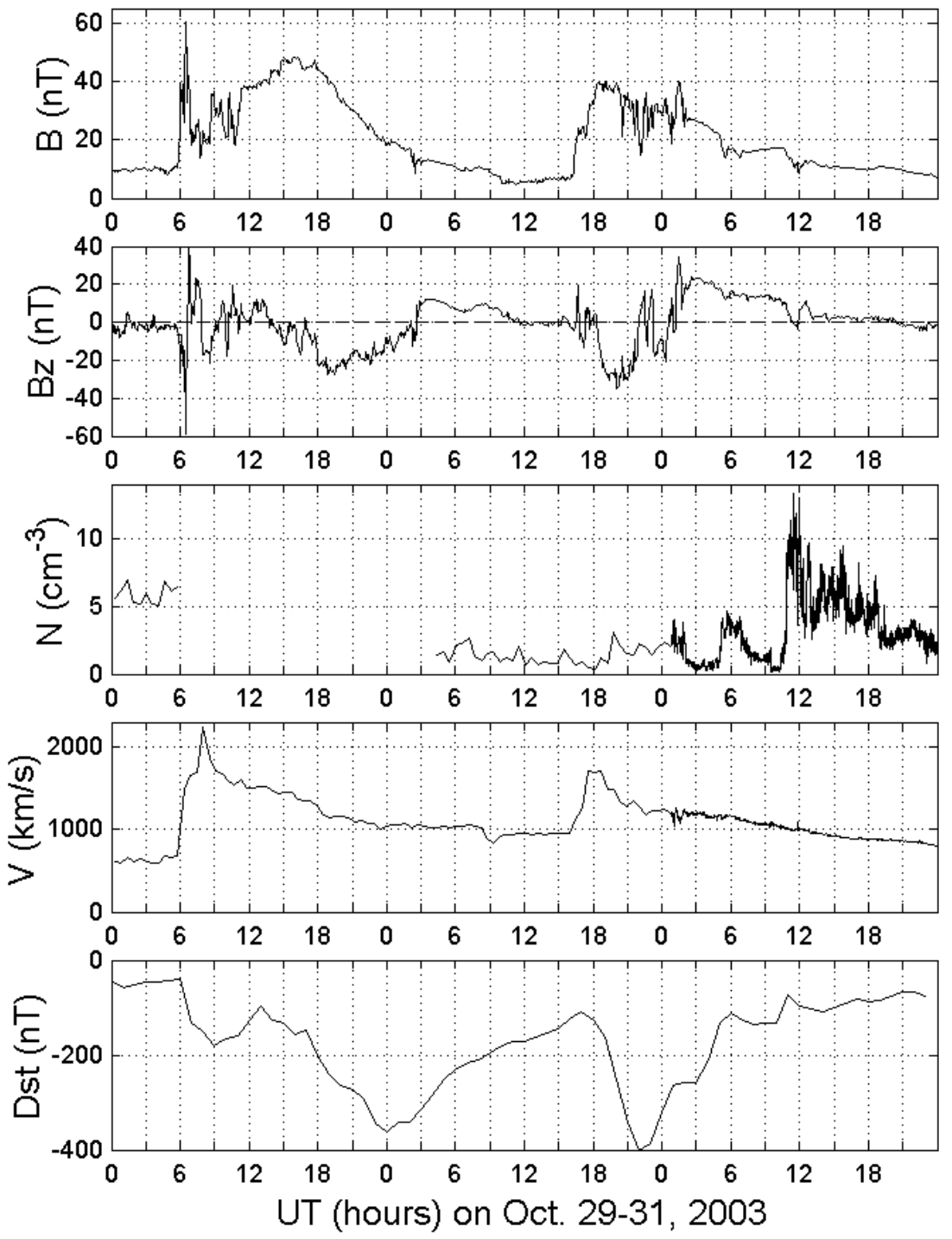

Figure 1 


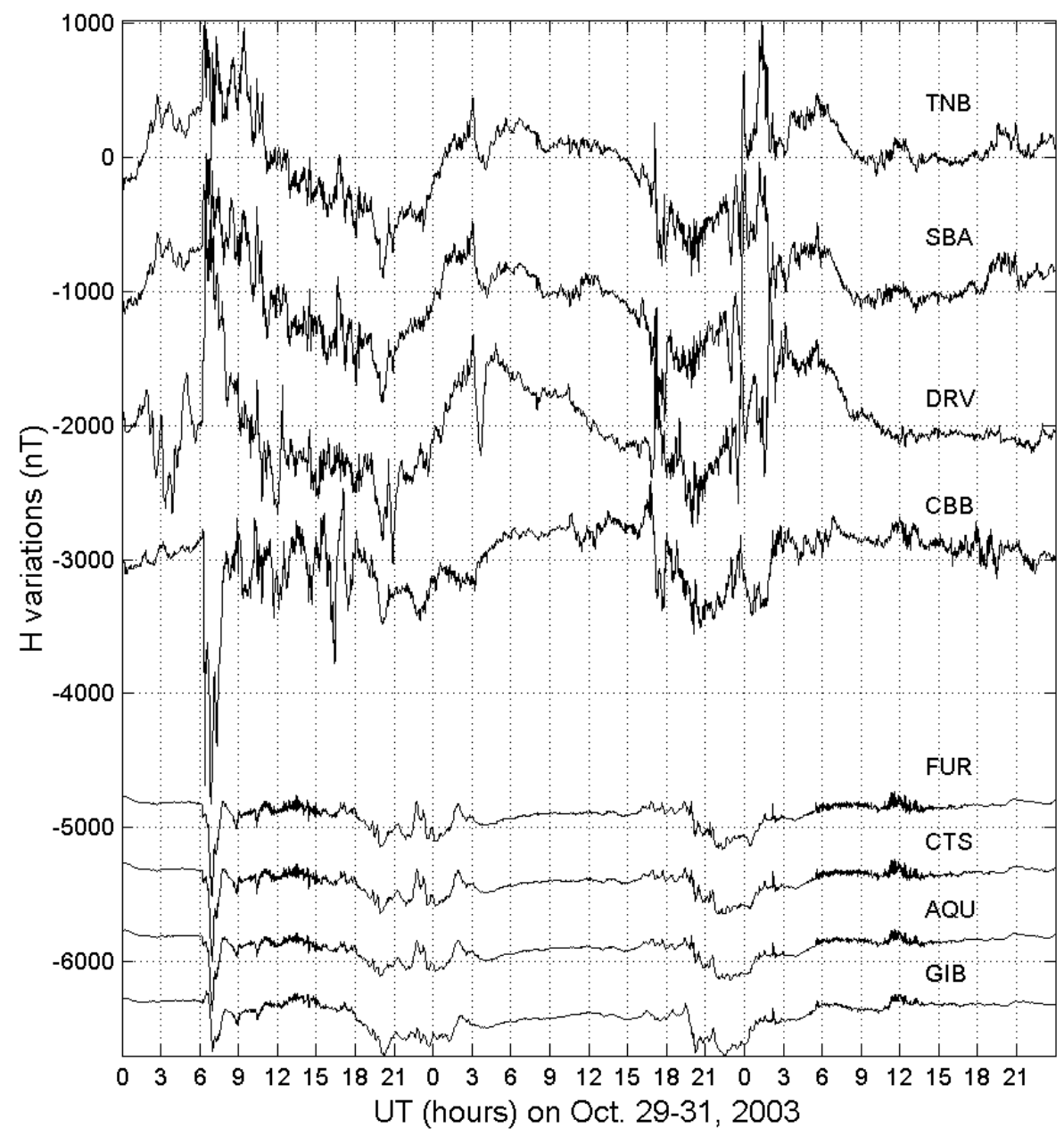

Figure 2. 


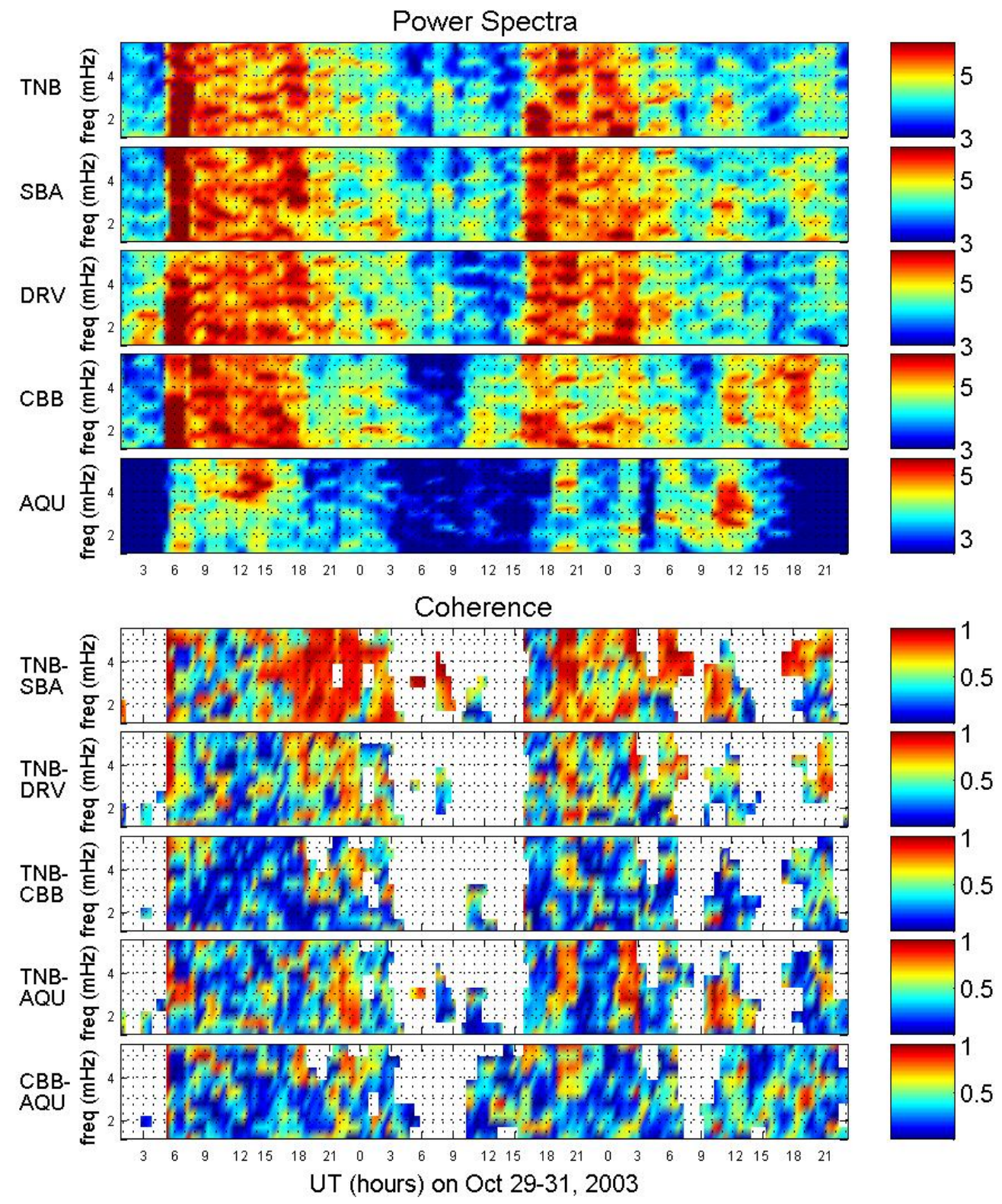

Figure 3. 

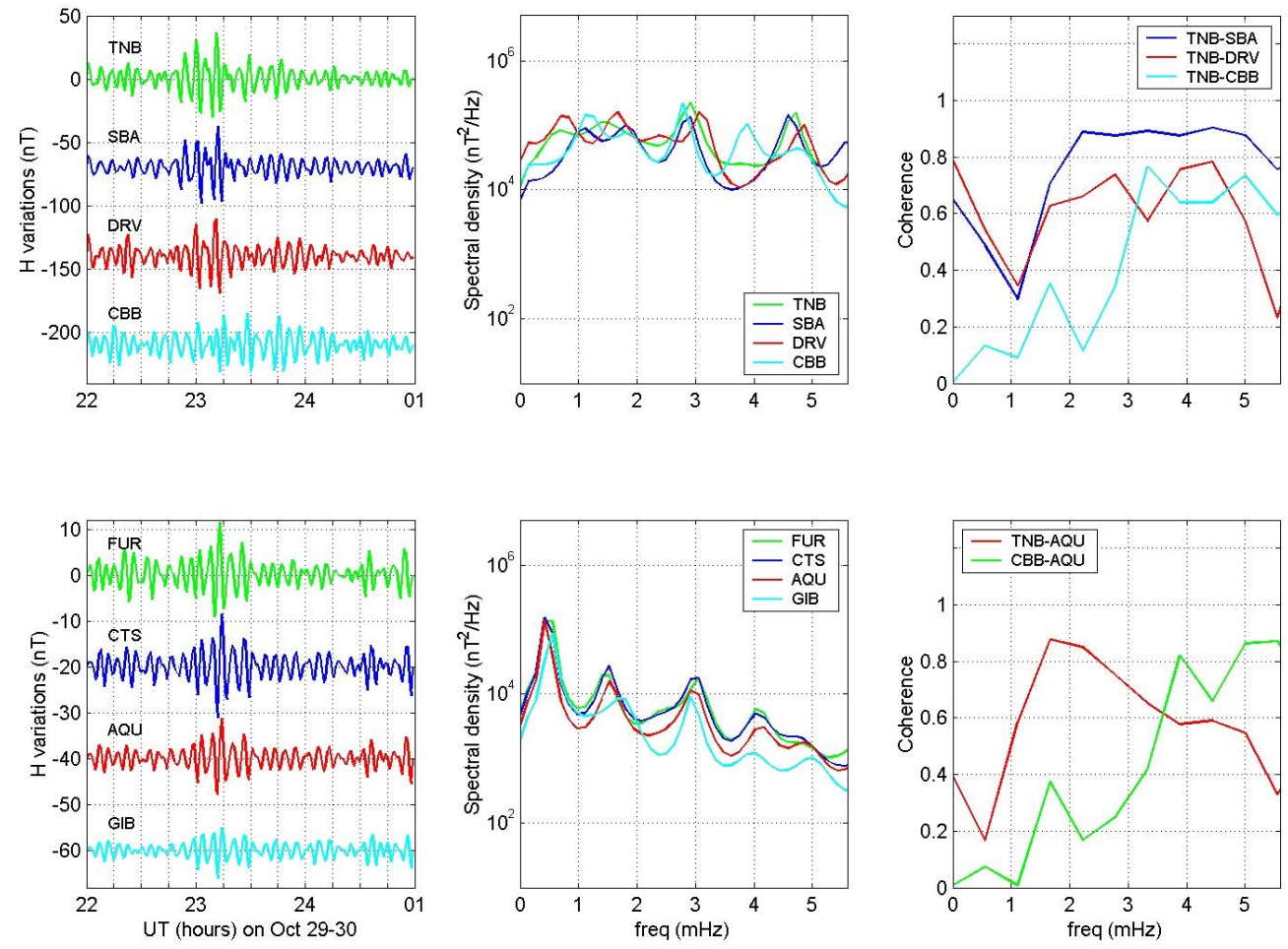

Figure 4. 

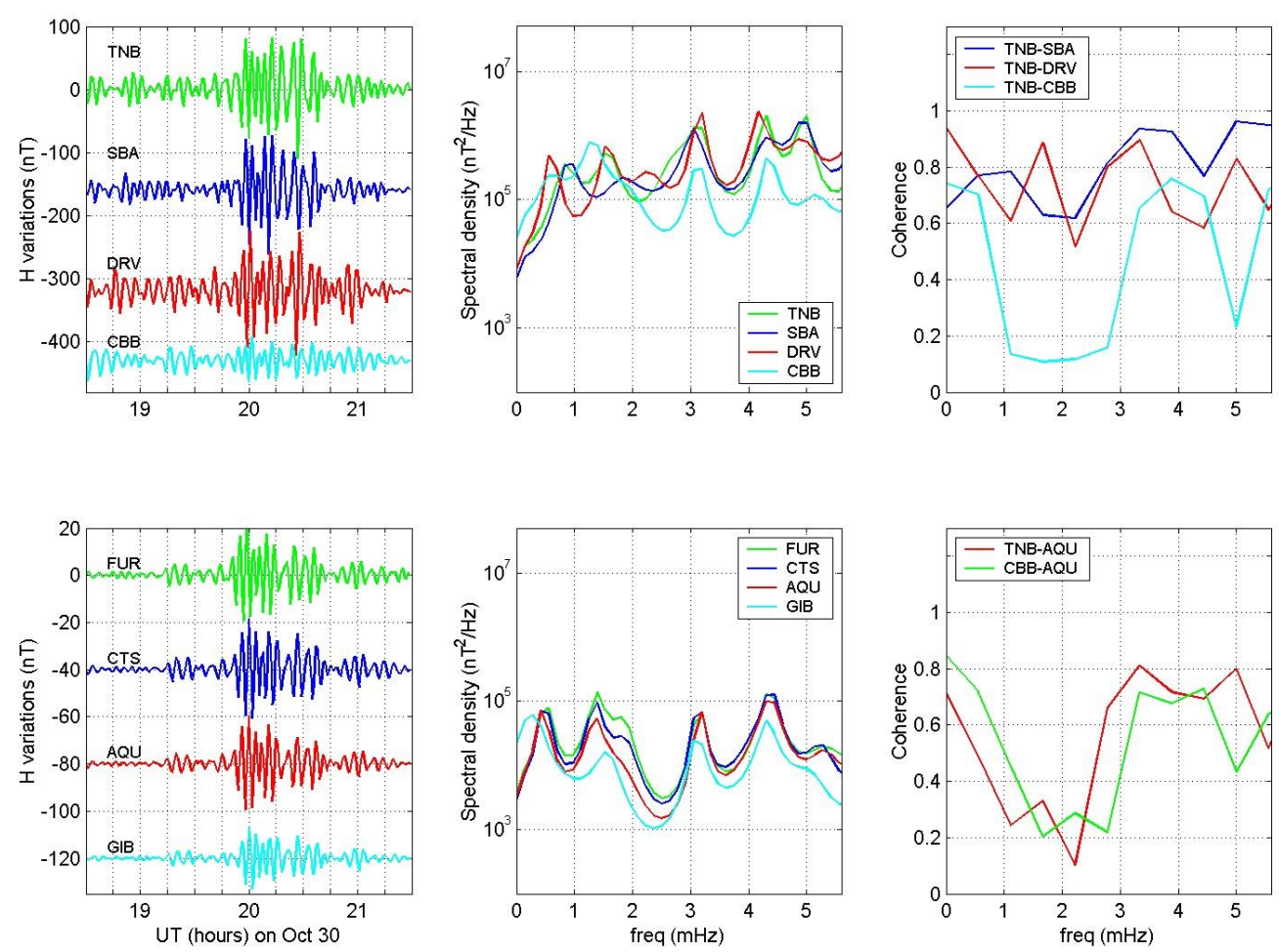

Figure 5. 

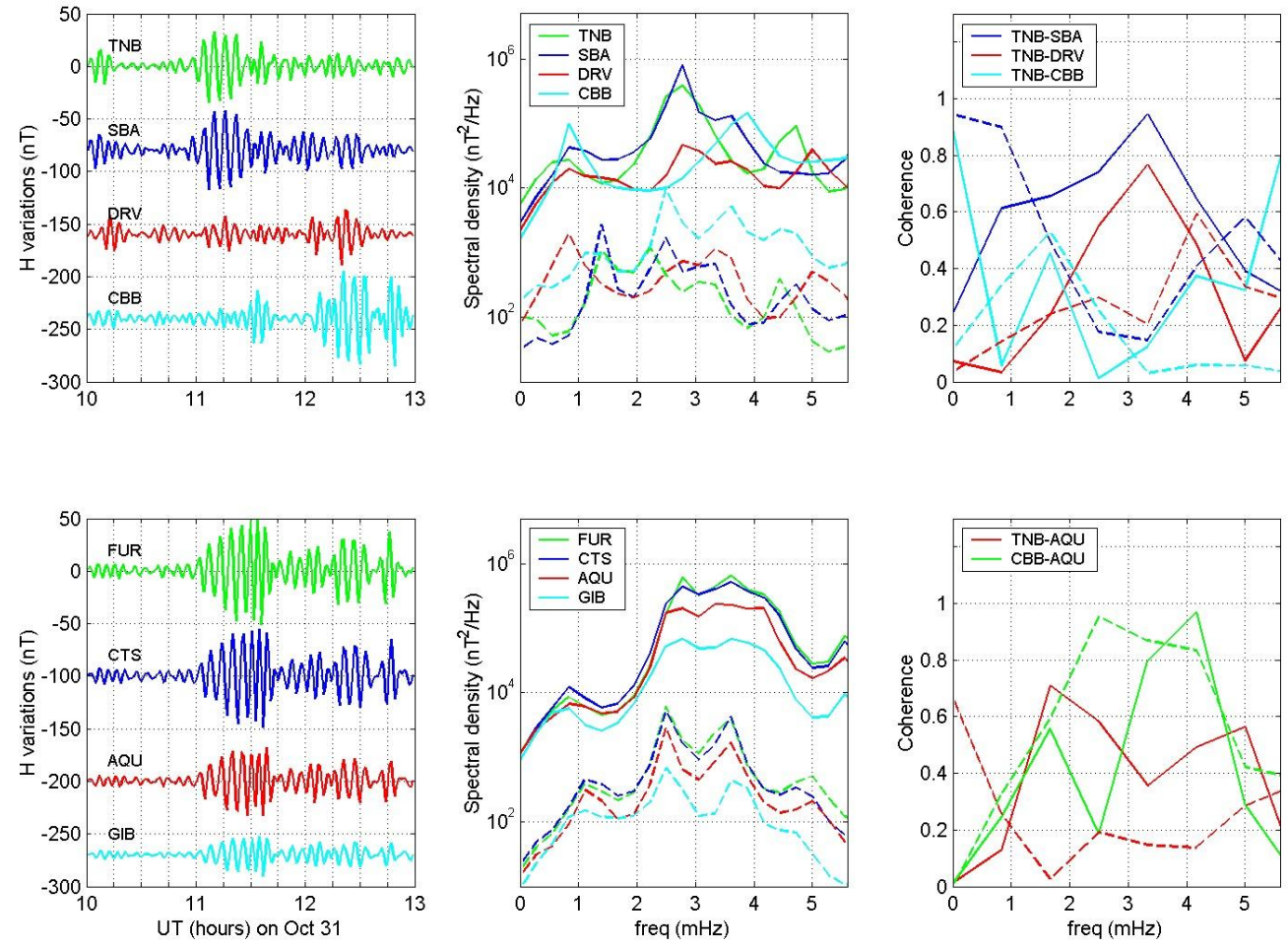

Figure 6. 